\title{
SENSORLESS DIRECT POWER CONTROL FOR THREE-PHASE GRID SIDE CONVERTER INTEGRATED INTO WIND TURBINE SYSTEM UNDER DISTURBED GRID VOLTAGES
}

Wind turbines with permanent magnet synchronous generator (PMSG) are widely used as sources of energy connected to a grid. The studied system is composed of a wind turbine based on PMSG, a bridge rectifier, a boost converter, and a controlled inverter to eliminate low-order harmonics in grid currents under disturbances of grid voltage. Traditionally, the grid side converter is controlled by using the control VFOC (Virtual Flux Oriented Control), which decouple the three-phase currents indirect components (id) and in quadratic (iq) and regulate them separately. However, the VFOC approach is dependent on the parameters of the system. This paper illustrates a new scheme for the grid-connected converter controller. Voltage imbalance and harmonic contents in the three-phase voltage system cause current distortions. Hence, the synchronization with the network is an important feature of controlling the voltage converter. Thus, a robust control method is necessary to maintain the adequate injection of the power during faults and/or a highly distorted grid voltage. The proposed new control strategy is to use the direct power control based virtual flux to eliminate side effects induced by mains disturbances. This control technique lowers remarkably the fluctuations of the active and reactive power and the harmonic distortion rate. The estimated powers used in the proposed control approach is calculated directly by the positive, negative, and harmonic items of the estimated flux and the measured current without line sensor voltage. References 27 , tables 6 , figures 13 .

Key words: direct power control based virtual flux, disturbances of grid voltage, permanent magnet synchronous generator.

Ветряные турбины с синхронным генератором на постоянных магнитах (PMSG) широко используются в качестве источников энергии, подключенных к сети. Исследуемая система состоит из ветряной турбины на основе PMSG, мостового выпрямителя, повышающего преобразователя и управляемого инвертора для устранения гармоник низкого порядка в токах сетки при возмущениях напряжения сети. Традиционно преобразователь на стороне сети управляется с помощью виртуального потокоориентированного управления VFOC (Virtual Flux Oriented Control), который разделяет трехфазные токи на косвенные компоненты (id) и на квадратичные компоннеты (iq) и регулирует их отдельно. Однако подход VFOC зависит от параметров системы. Данная статья иллюстрирует новую схему для контроллера преобразователя, подключенного к сети. Дисбаланс напряжения и содержание гармоник в трехфазной системе напряжения вызывают искажения тока. Следовательно, синхронизация с сетью является важной особенностью управления преобразователем напряжения. Таким образом, надежный метод управления необходим для поддержсания адекватной подачи энергии во время неисправностей и/или значительно искаженного напряжения сети. Предложенная новая стратегия управления заключается в использовании виртуального потока на основе прямого управления мощностью для устранения побочных эффектов, вызванных помехами в сети. Этот метод управления значительно снижает колебания активной и реактивной мощности и уровень гармонических искажений. Оценочные мощности, используемые в предлагаемом подходе к управлению, рассчитываются непосредственно по положительным, отрицательным и гармоническим элементам оцененного потока и измеренного тока без напряжения линейного датчика. Библ. 27, табл. 6, рис. 13.

Ключевые слова: виртуальный поток на основе прямого управления мощностьо, возмущения напряжения сети, синхронный генератор с постоянными магнитами.

Introduction. Renewable sources connected to a grid with their inherent intermittent behavior inevitably impose a major challenge to the conception of the controller voltage source converter. The majority of control approaches have equivocal statements according to their performance under conditions of non-ideal voltage grid prevailing in an integrated micro-grid system with renewable energy. Renewable energy production has become a significant development trend for contemporary grids because of environmental concerns. Wind energy is one of the important sources of renewable energy and is a fast-growing technology $[1,2]$. There are two types of wind energy systems: the grid-connected system and the stand-alone wind system. Actually, the application of grid-connected is largely preferred to stand-alone wind systems. The most common configuration for MWT systems connected to the grid of less than $20 \mathrm{~kW}$ normally consists of a high-pole-pair PMSG supplying a three-phase rectifier followed by a boost converter and an inverter [3]. At the generator terminals, a diode bridge rectifier can be used since no external excitation current is required. The non-controlled rectifier with a boost converter or supercharged converter serves to regulate the rotor voltage or speed. The interfaces between renewable energy sources and a grid-side have played a crucial role in terms of reliability, the flexibility of connection, and quality of energy and gradually attracted attention from the academic and the industrial worlds these last years. These interfaces can regulate the powers with a constant power factor or constant currents. Various studies of these electronic power interfaces and control methodologies have been largely realized, including the development of schemas of switching to improve the quality of the energy [4]. Traditionally, the grid side converter is controlled by using the control VFOC (Virtual Flux Oriented Control) [5] or VOC [6], which decouple the three-phase currents in Direct components (id) and in quadratic (iq) and regulate them separately. A reference frame aligned with the rotary vectors voltage or virtual flux [7]. However, the VFOC or VOC approaches are dependent on the parameters of the system and various simplifying approximations are made; for instance, the magnetic saturation of the inductor is not considered that is, the

(C) I. Boukhechem, A. Boukadoum, L. Boukelkoul, R. Lebied 
inductor is constant whatever of the current values [8]. The three-phase rectifier control approaches in width of impulse can be classified, as quoted in the literature, as vector control (VOC) and direct power control (DPC) [16]. The vector control (VC) can be based on grid side voltage [17-19] or virtual flux (VF) [20] using integral proportional controllers (PI). However, it offers some disadvantages, such as its addiction to the variation of system parameters, and that its performance largely depends on the agreement of the PI parameters. The direct power control strategy (DPC) has become one of the most recent research topics in recent years relying on its fast dynamic response, its a simple structure, and its high power factor [21, 22]. In DPC schemes developed, instant active and reactive powers are directly controlled [24]. This is what we need more than sensors (voltage sensors and AC mains sensors) that not only raises the volume and cost of the system but also lowers the reliability of the system [22]. The grid-connected three-phase rectifier can be seen as a virtual AC motor, its virtual flux link can be used to estimate the voltage of the rectifier [26]. Virtual flux (VF) based schematics are popular in voltage-free controller designs for the following two reasons. The application of VF remains the common benefits of sensorless strategies, such as cost reduction, reliability, and overall improvement. During this time, it eliminates the orientation point limitation for the control system [25] and improves the harmonic tolerance [26]. A more complete comparative study is conducted to evaluate the performance of the system in different grid voltage conditions where the voltage unbalances vary by up to $20 \%$ and the distortion varies by $10 \%$. The global magnitude of total harmonic distortion (THD) presented by VF-DPC and the resilient direct power control RV-DPC is always inferior to that of V-DPC [15]. The $\mathrm{V}$-DPC possesses a low immunity to asymmetric and deformed voltage; the VF-DPC shows a better reliability only under distorted grid voltage [15] a new method of VF-DPC control based on the virtual flux estimate Capable of handling these problems; it results in a stable and regular estimated virtual flux with a sectorial detection at a high precision [23].

The aim of this article is to inject all the power provided by a wind turbine based on the PMSG is a threephase microgrid subjected to various voltage conditions. This document also seeks to propose a new strategy by integrating new theory, Direct Power Control, based on the virtual flux (VF_DPC) to ensure that the injected currents in the three-phase grid emulate the sinusoidal forms even when the grid voltage is no longer ideal.

Modeling of The Wind Conversion. In the suggested system of energy, the PMSG is plugged to the grid through an inverter assisted by a rectifier bridge and a boost converter (Fig. 1). The rectifier consisted of diodes that convert the AC output voltage from PMSG to a DC voltage. The boost converter increases the output rectifier voltage at a regulated DC level. The boost converter regulates the speed of the generator or the active power of the generator to capture the maximum power of available wind energy. The grid-side converter (GSC) is then utilized to control the DC link voltage and transfer all the active power provided by the turbine to the grid.

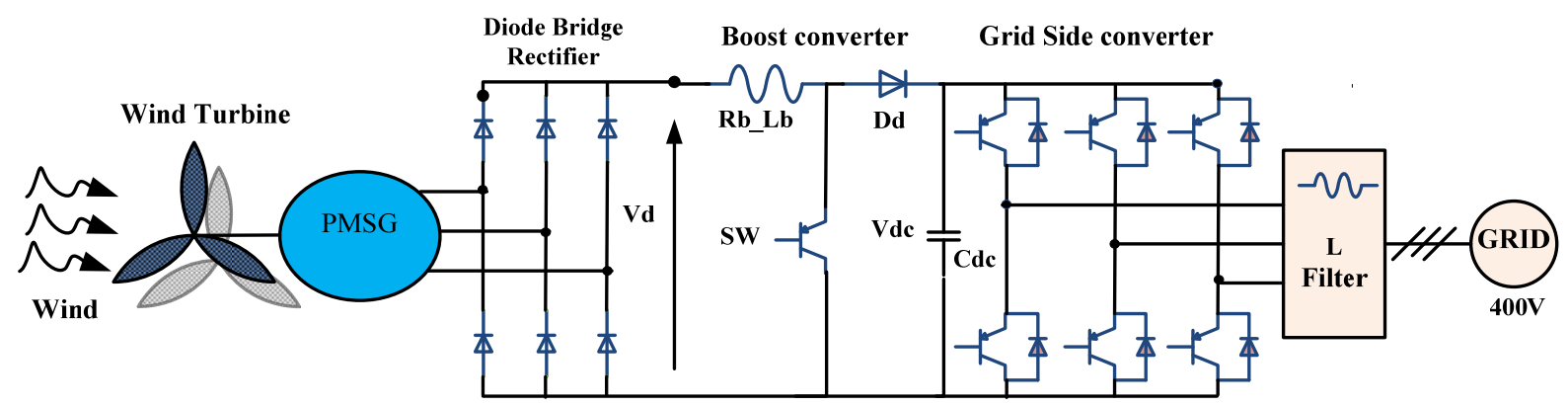

Fig. 1. The system under study comprising PMSG assisted with diode rectifier and boost converter

Wind Turbine Modeling. The wind turbine is three-dimensional, with complex shapes in movement, inundated in a stream air; it changes over the wind's motor vitality and conveys mechanical force portrayed by a rotating speed and mechanical torque. The dynamic force accessible to the turbine is given by:

$$
P_{\omega}=\frac{1}{2} \rho S V_{\omega}^{3}=\frac{1}{2} \rho \pi R^{2} V_{\omega}^{3},
$$

where $\rho$ is density of air $\left(1.25 \mathrm{~kg} / \mathrm{m}^{3}\right), S$ is area swept by the turbine $\left(\mathrm{m}^{2}\right), R$ is turbine radius $(\mathrm{m}), V_{\omega}$ is wind speed $(\mathrm{m} / \mathrm{s})$.

Aerodynamic shaft power is given by:

$$
P_{\text {turb }}=C_{p} P_{\omega}=\frac{1}{2} \rho \pi R^{2} V_{\omega}^{3} C_{p}(\lambda, \beta),
$$

where $C_{p}$ is the power coefficient which is a function of the pitch angle of rotor blades and of the tip speed ratio; $\beta$ is orientation angle of the blades; $\lambda$ is specific speed

$$
\lambda=\frac{\omega_{\text {turb }} R}{V_{\omega}},
$$

where $\omega_{t u r b}$ is speed of the turbine.

Modeling of PMSG. The model of PMSG in $\mathrm{d}-\mathrm{q}$ transformation is given by the accompanying voltage framework condition

$$
\begin{gathered}
V_{d}=-R_{s} I_{d}-L_{d} \frac{d}{d t} I_{d}+\omega L_{q} I_{q} ; \\
V_{q}=-R_{s} I_{q}-L_{q} \frac{d}{d t} I_{q}+\omega L_{d} I_{d}+\omega \varphi_{f} .
\end{gathered}
$$

The electromagnetic coupling

$$
\left\{\begin{array}{l}
\varphi_{d}=L_{d} i_{d}+\varphi_{f} ; \\
\varphi_{q}=L_{q} i_{q},
\end{array}\right.
$$

where $L_{d}$ is stator inductance in d-axis, $L_{q}$ is stator inductance in q-axis, $L_{q}$ and $L_{d}$ are supposed independent of $\theta, \varphi_{f}$ is magnet flux. 
Equation (6) represent the expression of electromagnetic torque:

$$
\begin{aligned}
& V_{d}=-R_{s} I_{d}-C_{e m}= \\
& =\frac{3}{2} p\left[\left(L_{d}-L_{q}\right) i_{d} i_{q}+i_{q} \varphi_{f}\right] L_{d} \frac{d}{d t} I_{d}+\omega L_{q} I_{q} ; \\
& V_{q}=-R_{s} I_{q}-L_{q} \frac{d}{d t} I_{q}+\omega L_{d} I_{d}+\omega \varphi_{f},
\end{aligned}
$$

in which $C_{e m}=3 / 2 \cdot p \cdot \varphi_{f} \cdot I_{q}$, where $p$ is the pole pair number; $R_{s}$ is stator resistance; $V_{d}$ and $V_{q}$ are stator voltage components; $I_{d}$ and $I_{q}$ are stator current components.

Control Of Boost Converter. At the output of certain renewable sources (such as wind systems) in general, the voltage generated is not enough to ensure the proper functioning of the inverter. For this, a DC/DC boost converter must be used, built with electronic semiconductor devices, an inductor and a capacitor in parallel [12]. The wind generator is tied to a boost converter, and its input voltage is controlled so that the wind generator delivers the maximum power to its output terminals. The boost converter is connected between the output terminals of the non-controlled rectifier and the input of the inverter, as shown in Fig. 2.

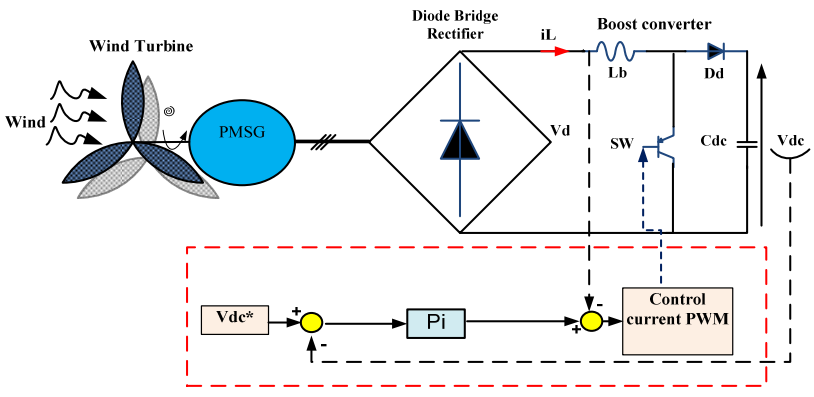

Fig. 2. Structure and principle control of an $\mathrm{AC} / \mathrm{DC}$ converter

The essential role of the boost converter is to convert the variable input DC voltage, due to different operating conditions, to a suitable constant DC voltage. The DC link voltage can be maintained constant at the reference value by adjusting the duty cycle of the converter. In doing so, the DC voltage is controlled to sufficient and non-fluctuating levels so that maximum power is injected under better conditions through the grid side inverter. The control framework of the DC-DC boost converter is founded on the use of the PI controller to keep the DC link voltage at the reference value as shown in Fig. 2. The voltage/current input/output relationship of the boost converter can be written as [13].

Direct Power Control Based On Virtual Flux (VF_DPC). In this situation, the direct power control based on the virtual flux (DPC-VF) is used instead of the direct power control (DPC). This control technique greatly lowers the fluctuations of the active and reactive power and the harmonic distortion rate THD, keeping the advantage of control without the line voltage sensor. In the VF concept, the virtual AC motor is assumed from the behavior of grid voltages and $\mathrm{AC}$ side coupling impedance with inductance $L$ in series with equivalent resistance $R$. As a result, $L$ and $R$ are analogous to the leakage inductance and the stator resistance of an $\mathrm{AC}$ motor, respectively [26]. The control of the active $\left(P_{r e f}\right)$ and reactive $\left(Q_{r e f}\right)$ power are compared with the estimated active and reactive power values $\left(P_{e s}\right.$ and $\left.Q_{e s}\right)$ by hysteresis controllers, respectively. The output digitized signals (SP) and (SQ) and the vector position $\left(\theta_{\varphi}\right)$ make it possible to select the appropriate voltage vector according to the switching table defined in [24].

Figure 3 shows the maximum power point tracking (MPPT) control charts for the optimal torque control method respectively. The torque reference multiplied by the speed of the turbine $(\omega t)$ gives the optimal power reference. As shown in Fig. 3, the maximum power of the wind turbine is calculated from the equation $\left[P_{\text {ref }}{ }^{*}=T_{r e f}{ }^{*} \cdot \omega t\right]$ which represents the power reference injected into the grid.

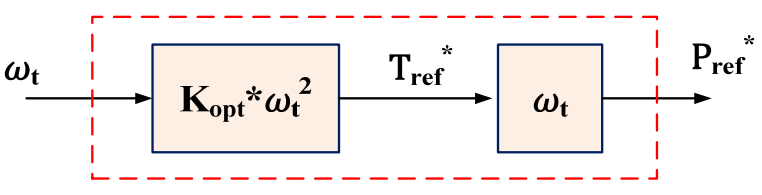

Fig. 3. Block diagram of MPPT Optimal torque control

Model of Grid Side Converter. The vector of virtual flux $\varphi_{\alpha \beta}$ can be estimated from the integration of the vector of grid voltages $e_{\alpha \beta}$ as indicated follow in equation (8).

The voltages of the converter (Fig. 4) are estimated in the block ais follows

$$
\left\{\begin{array}{c}
V_{s \alpha}=\sqrt{\frac{2}{3}} V_{d c} \times\left(S_{a}-\left(S_{b}+S_{c}\right)\right) ; \\
V_{s \beta}=\sqrt{\frac{1}{2}} V_{d c} \times\left(S_{b}-S_{c}\right),
\end{array}\right.
$$

where $S_{a}, S_{b}$, and $S_{c}$ are the switching states of the rectifier and $\left(V_{s \alpha}, V_{s \beta}\right)$ are the AC side voltages of the converter. $V_{d c}$ is rectified voltage.

The components of the virtual flux $\varphi_{s}$ are calculated as follows:

$$
\left\{\begin{array}{l}
\varphi_{s \alpha}=\int\left(V_{s \alpha}+L \frac{d i_{\alpha}}{d t}\right) d t ; \\
\varphi_{s \beta}=\int\left(V_{s \beta}+L \frac{d i_{\beta}}{d t}\right) d t,
\end{array}\right.
$$

where $V_{s(\alpha \beta)}$ is the voltage at the output of the inverter at the $\alpha, \beta$ mark; $i_{\alpha}$ and $i_{\beta}$ are grid currents in the Concordia.

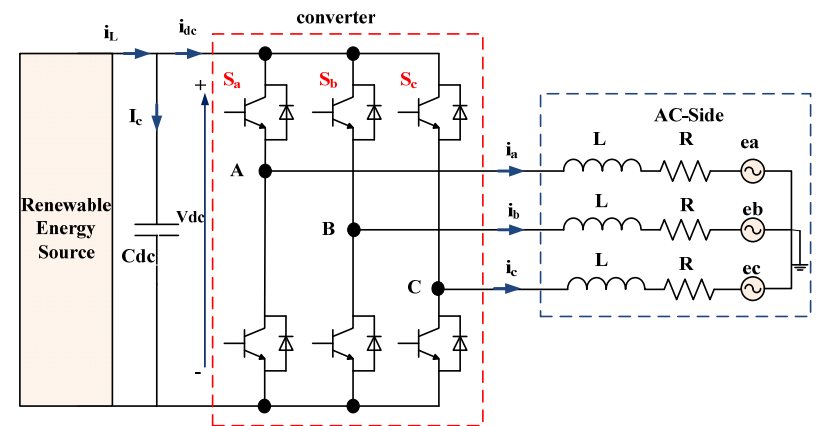

Fig. 4. Simplified representation of a three-phase PWM inverter

The virtual flux concept has been developed for a better estimate of instantaneous active and reactive power in AC-free sensor operation. The use of an ideal integrator for computing the virtual flux produces a DC offset. According to (7) and (8) the integrator can be used to 
estimate the virtual flux, but the initial value of the flux has to be estimated first, this complicates the simulation and the DC offset could be produced easily [14]. The virtual line stream observer (Fig. 5) shows that the new algorithm responds faster than traditional control.

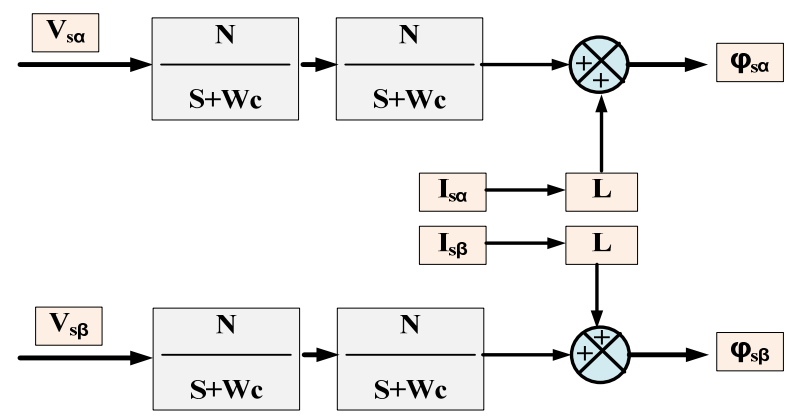

Fig. 5. The virtual line flux linkage observer

The active and instantaneous reactive powers are observed in the (power observer block) by the measurement of the line current and the observation of the virtual flux components in equation [9]. Instant active and reactive powers can be estimated as

$$
\left\{\begin{array}{l}
P_{e s}=\omega\left(\varphi_{s \alpha} \times i_{s \beta}-\varphi_{s \beta} \times i_{s \alpha}\right) \\
Q_{e s}=\omega\left(\varphi_{s \alpha} \times i_{s \alpha}+\varphi_{s \beta} \times i_{s \beta}\right) .
\end{array}\right.
$$

There is a change in the sector. These sectors may be expressed as follows (Fig. 6)

$$
(N-5) \frac{\pi}{6} \prec \theta_{N} \prec(N-4) \frac{\pi}{6} .
$$

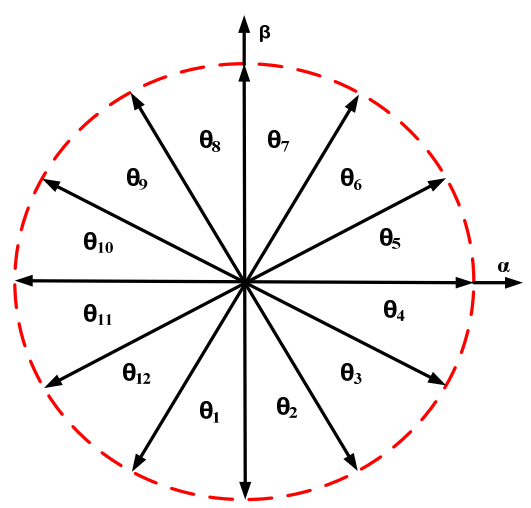

Fig. 6. Virtual flux plane 12 sectors

The position of the VF vector

$$
\theta_{N}=\tan ^{-1}\left(\frac{\varphi_{s \beta}}{\varphi_{s \alpha}}\right)
$$

is used in the VF-DPC scheme to select the appropriate converter voltage vector according to the switch table defined in Table 1.

Table 1

Switching Table

\begin{tabular}{|l|l|l|l|l|l|l|l|l|l|l|l|l|l|}
\hline$S_{p}$ & $S_{q}$ & $\theta_{1}$ & $\theta_{2}$ & $\theta_{3}$ & $\theta_{4}$ & $\theta_{5}$ & $\theta_{6}$ & $\theta_{7}$ & $\theta_{8}$ & $\theta_{9}$ & $\theta_{10}$ & $\theta_{11}$ & $\theta_{12}$ \\
\hline 1 & 0 & $\mathrm{~V}_{5}$ & $\mathrm{~V}_{6}$ & $\mathrm{~V}_{6}$ & $\mathrm{~V}_{1}$ & $\mathrm{~V}_{1}$ & $\mathrm{~V}_{2}$ & $\mathrm{~V}_{2}$ & $\mathrm{~V}_{3}$ & $\mathrm{~V}_{3}$ & $\mathrm{~V}_{4}$ & $\mathrm{~V}_{4}$ & $\mathrm{~V}_{5}$ \\
\hline & 1 & $\mathrm{~V}_{3}$ & $\mathrm{~V}_{4}$ & $\mathrm{~V}_{4}$ & $\mathrm{~V}_{5}$ & $\mathrm{~V}_{5}$ & $\mathrm{~V}_{6}$ & $\mathrm{~V}_{6}$ & $\mathrm{~V}_{1}$ & $\mathrm{~V}_{1}$ & $\mathrm{~V}_{2}$ & $\mathrm{~V}_{2}$ & $\mathrm{~V}_{3}$ \\
\hline 0 & 0 & $\mathrm{~V}_{6}$ & $\mathrm{~V}_{1}$ & $\mathrm{~V}_{1}$ & $\mathrm{~V}_{2}$ & $\mathrm{~V}_{2}$ & $\mathrm{~V}_{3}$ & $\mathrm{~V}_{3}$ & $\mathrm{~V}_{4}$ & $\mathrm{~V}_{4}$ & $\mathrm{~V}_{5}$ & $\mathrm{~V}_{5}$ & $\mathrm{~V}_{6}$ \\
\hline & 1 & $\mathrm{~V}_{1}$ & $\mathrm{~V}_{2}$ & $\mathrm{~V}_{2}$ & $\mathrm{~V}_{3}$ & $\mathrm{~V}_{3}$ & $\mathrm{~V}_{4}$ & $\mathrm{~V}_{4}$ & $\mathrm{~V}_{5}$ & $\mathrm{~V}_{5}$ & $\mathrm{~V}_{6}$ & $\mathrm{~V}_{6}$ & $\mathrm{~V}_{1}$ \\
\hline
\end{tabular}

Modified Direct Power Control (M DPC) for Converter. When the grid is unbalanced and harmonized, according to the theory of symmetrical decomposition, an unbalanced and distorted three-phase system can be decomposed into three symmetrical components: the positive sequence, the negative sequence, and the zero sequence.

In fixed reference systems the flux and the measured current are expressed as

$$
\begin{aligned}
& \left\{\begin{array}{l}
\varphi_{s \alpha}=\left(\varphi_{s \alpha}^{+}+\varphi_{s \alpha}^{-}+\varphi_{s \alpha}^{h}\right) \\
\varphi_{s \beta}=\left(\varphi_{s \beta}^{+}+\varphi_{s \beta}^{-}+\varphi_{s \beta}^{h}\right)
\end{array}\right. \\
& \left\{\begin{array}{l}
i_{s \alpha}=\left(i_{s \alpha}^{+}+i_{s \alpha}^{-}+i_{s \alpha}^{h}\right) \\
i_{s \beta}=\left(i_{s \beta}^{+}+i_{s \beta}^{-}+i_{s \beta}^{h}\right)
\end{array}\right.
\end{aligned}
$$

According to the theory of symmetric decomposition:

$$
\left[\begin{array}{l}
X^{+} \\
X^{-}
\end{array}\right]=\frac{1}{3}\left[\begin{array}{ccc}
1 & a & a^{2} \\
1 & a^{2} & a
\end{array}\right]\left[\begin{array}{c}
X_{a} \\
X_{b} \\
X_{c}
\end{array}\right]
$$

here the indices $(+)$ and $(-)$ indicate the positive sequence and the negative sequence, $a=e^{j\left(\frac{2 \pi}{3}\right)}$, the zero sequence is $X^{h}=X-X^{+}-X$.

After substituting the flux and the current by their values indicated in (10) and (11), the results of the active and reactive powers can be grouped as follows

$$
\begin{aligned}
& P_{e s}=\omega \times\left[\begin{array}{c}
\left(\varphi_{s \alpha}^{+}+\varphi_{s \alpha}^{-}+\varphi_{s \alpha}^{h}\right) \times\left(i_{s \beta}^{+}+i_{s \beta}^{-}+i_{s \beta}^{h}\right)- \\
-\left(\varphi_{s \beta}^{+}+\varphi_{s \beta}^{-}+\varphi_{s \beta}^{h}\right) \times\left(i_{s \alpha}^{+}+i_{s \alpha}^{-}+i_{s \alpha}^{h}\right)
\end{array}\right] ; \\
& P_{e s}=\omega \times\left[\begin{array}{l}
\left(\varphi_{s \alpha}^{+} \times i_{s \beta}^{+}-\varphi_{s \beta}^{+} \times i_{s \alpha}^{+}\right)+\left(\varphi_{s \alpha}^{-} \times i_{s \beta}^{-}-\varphi_{s \beta}^{-} \times i_{s \alpha}^{-}\right)+ \\
+\left(\varphi_{s \alpha}^{h} \times i_{s \beta}^{h}-\varphi_{s \beta}^{h} \times i_{s \alpha}^{h}\right)+\left(\varphi_{s \alpha}^{+} \times i_{s \beta}^{-}-\varphi_{s \beta}^{+} \times i_{s \alpha}^{-}\right)+ \\
+\left(\varphi_{s \alpha}^{+} \times i_{s \beta}^{h}-\varphi_{s \beta}^{+} \times i_{s \alpha}^{h}\right)+\left(\varphi_{s \alpha}^{-} \times i_{s \beta}^{+}-\varphi_{s \beta}^{-} \times i_{s \alpha}^{+}\right)+ \\
+\left(\varphi_{s \alpha}^{-} \times i_{s \beta}^{h}-\varphi_{s \beta}^{-} \times i_{s \alpha}^{h}\right)+\left(\varphi_{s \alpha}^{h} \times i_{s \beta}^{+}-\varphi_{s \beta}^{h} \times i_{s \alpha}^{+}\right)+ \\
+\left(\varphi_{s \alpha}^{h} \times i_{s \beta}^{-}-\varphi_{s \beta}^{h} \times i_{s \alpha}^{-}\right)
\end{array}\right] ; \\
& Q_{e s}=\omega \times\left[\begin{array}{c}
\left(\varphi_{s \alpha}^{+}+\varphi_{s \alpha}^{-}+\varphi_{s \alpha}^{h}\right) \times\left(i_{s \alpha}^{+}+i_{s \alpha}^{-}+i_{s \alpha}^{h}\right)+ \\
+\left(\varphi_{s \beta}^{+}+\varphi_{s \beta}^{-}+\varphi_{s \beta}^{h}\right) \times\left(i_{s \beta}^{+}+i_{s \beta}^{-}+i_{s \beta}^{h}\right)
\end{array}\right] ; \\
& Q_{e s}=\omega \times\left[\begin{array}{l}
\left(\varphi_{s \alpha}^{+} \times i_{s \alpha}^{+}+\varphi_{s \beta}^{+} \times i_{s \beta}^{+}\right)+\left(\varphi_{s \alpha}^{-} \times i_{s \alpha}^{-}+\varphi_{s \beta}^{-} \times i_{s \beta}^{-}\right)+ \\
+\left(\varphi_{s \alpha}^{h} \times i_{s \alpha}^{h}+\varphi_{s \beta}^{h} \times i_{s \beta}^{h}\right)+\left(\varphi_{s \alpha}^{+} \times i_{s \alpha}^{-}+\varphi_{s \beta}^{+} \times i_{s \beta}^{-}\right)+ \\
+\left(\varphi_{s \alpha}^{+} \times i_{s \alpha}^{h}+\varphi_{s \beta}^{+} \times i_{s \beta}^{h}\right)+\left(\varphi_{s \alpha}^{-} \times i_{s \alpha}^{+}+\varphi_{s \beta}^{-} \times i_{s \beta}^{+}\right)+ \\
+\left(\varphi_{s \alpha}^{-} \times i_{s \alpha}^{h}+\varphi_{s \beta}^{-} \times i_{s \beta}^{h}\right)+\left(\varphi_{s \alpha}^{h} \times i_{s \alpha}^{+}+\varphi_{s \beta}^{h} \times i_{s \beta}^{+}\right)+ \\
+\left(\varphi_{s \alpha}^{h} \times i_{s \alpha}^{-}+\varphi_{s \beta}^{h} \times i_{s \beta}^{-}\right)
\end{array}\right] .
\end{aligned}
$$

The target control of the DPC strategy is to eliminate the negative and harmonic components of the current, so we can force

$$
i_{s \alpha}^{-}=i_{s \beta}^{-}=i_{s \alpha}^{h}=i_{s \beta}^{h}=0 .
$$

Leading to 


$$
\begin{gathered}
P_{n e g}=\omega \times\left[\left(\varphi_{s \alpha}^{-} \times i_{s \beta}^{+}-\varphi_{s \beta}^{-} \times i_{s \alpha}^{+}\right)\right] ; \\
Q_{n e g}=\omega \times\left[\left(\varphi_{s \alpha}^{-} \times i_{s \alpha}^{+}+\varphi_{s \beta}^{-} \times i_{s \beta}^{+}\right)\right],
\end{gathered}
$$

where $P_{n e g}$ and $Q_{n e g}$ represent the interaction between the negative sequence and the positive sequence of flux and currents that generate oscillation in active and reactive power with a frequency of $2 \omega$.

So we have

$$
\begin{aligned}
& P_{h a r}=\omega \times\left[\left(\varphi_{s \alpha}^{h} \times i_{s \beta}^{+}-\varphi_{s \beta}^{h} \times i_{s \alpha}^{+}\right)\right] ; \\
& Q_{h a r}=\omega \times\left[\left(\varphi_{s \alpha}^{h} \times i_{s \alpha}^{+}+\varphi_{s \beta}^{h} \times i_{s \beta}^{+}\right)\right],
\end{aligned}
$$

where $P_{h a r}$ and $Q_{\text {har }}$ represent the interaction between the harmonic parts of the flux and the positive sequence of the currents.

It can be seen from equations $[16,17]$ that if we want to eliminate the effect of the negative and harmonic components of the unbalanced and deformed grid, the active and reactive power of compensation can be obtained as

$$
\begin{aligned}
& P_{c o m}=\omega \times\left[\left(\varphi_{s \alpha}^{-} \times i_{s \beta}^{+}-\varphi_{s \beta}^{-} \times i_{s \alpha}^{+}\right.\right. \\
& Q_{c o m}=\omega \times\left[\left(\begin{array}{l}
\left.\left.\varphi_{s \alpha}^{h} \times i_{s \beta}^{+}-\varphi_{s \beta}^{h} \times i_{s \alpha}^{+}\right)\right) ; \\
\varphi_{s \alpha}^{-} \times i_{s \alpha}^{+}+\varphi_{s \beta}^{-} \times i_{s \beta}^{+}
\end{array}\right)+\left(\begin{array}{l}
h \\
\varphi_{s \alpha}^{h} \times i_{s \alpha}^{+}+\varphi_{s \beta}^{h} \times i_{s \beta}^{+}
\end{array}\right)\right]
\end{aligned}
$$

Figure 7 shows the overall configuration of the direct power control without a voltage sensor based on the virtual flux.

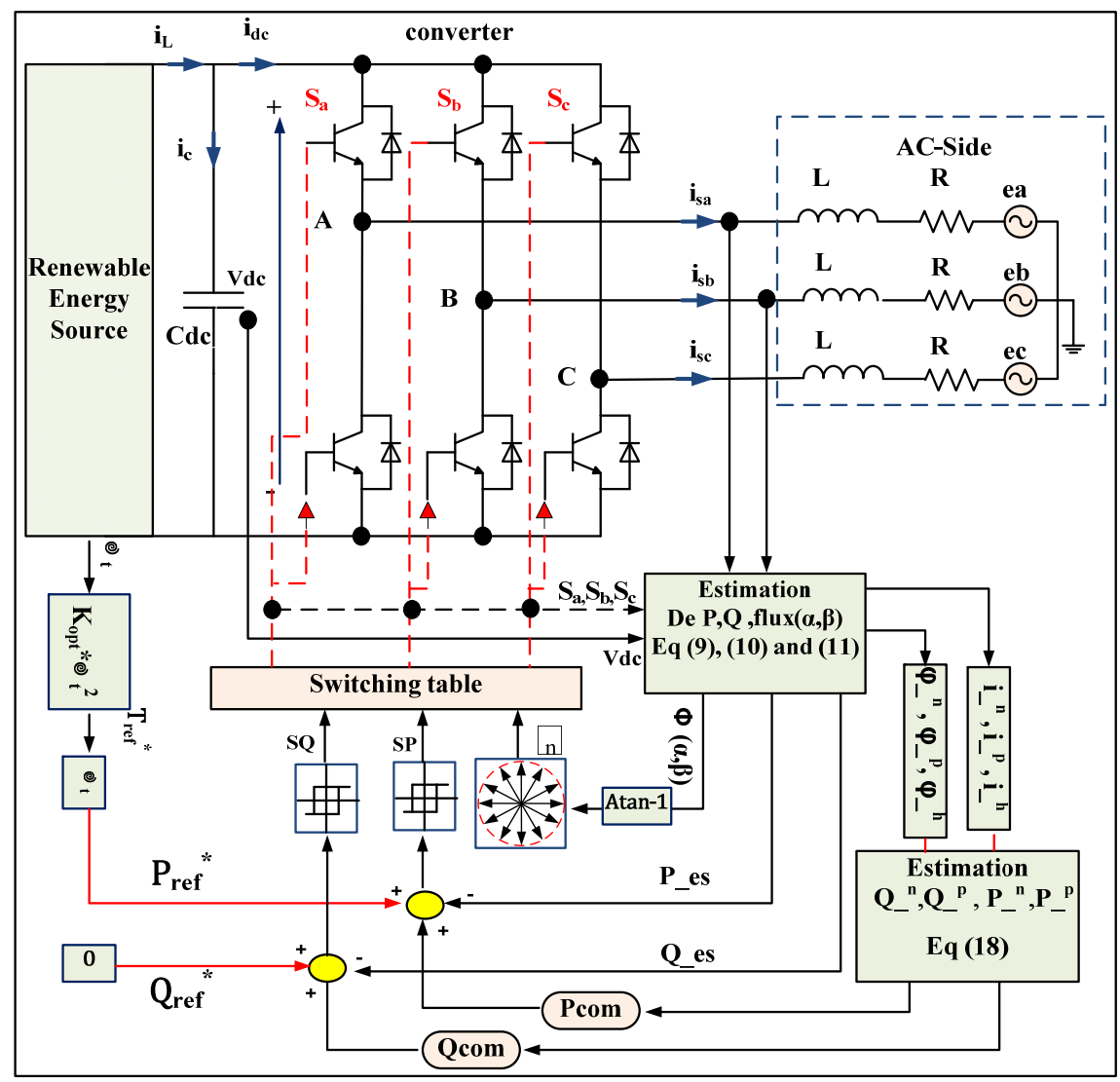

Fig. 7. Control block diagram of the grid-side converter

Simulation Results. In order to verify the performance of the optimal VF-DPC proposed on a twolevel voltage source inverter, simulation studies were performed in the Matlab/Simulink environment under various grid voltage conditions. All the results are obtained at the maximum power of the wind turbine $P_{\text {ref }}{ }^{*}[\mathrm{~W}]$ and $Q_{\text {ref }}{ }^{*}$ of 0 [VAR].

The simulation model is developed from a Kollmorgen $6 \mathrm{~kW}$ industrial permanent magnet synchronous machine [27]. The values of the turbine and the PMSG used parameters are given in Appendix in Table A.1 and Table A.2. The converter power and its monitoring algorithm are also implemented and included in the model. The sampling time used for the simulation is $2 \cdot 10^{-5} \mathrm{~s}$.

Test 1. Maximum Power Generation injected. In this test, the purpose of the algorithm is to follow the maximum power of the system. Fig. 8 and 9 show several results obtained.

Figure 8 shows the system response for a gradual change in wind speed from $9 \mathrm{~m} / \mathrm{s}$ to $7.5 \mathrm{~m} / \mathrm{s}$ to $8 \mathrm{~m} / \mathrm{s}$ then back to $9.5 \mathrm{~m} / \mathrm{s}$. It can be seen in Fig. 8,d that the electromagnetic torque of the generator $T_{g}$ also follows the reference torque of the turbine $T_{m}$. Figures $8, c$ and $8, e$ show that the voltage of the PMSG varies with wind speed as well as the DC voltage at the output of the rectifier. Figure $8, f$ shows that the current is controlled according to the MPPT strategy and can be better regulated to reach the optimum current. Figure $8, g$ illustrates that the DC capacitor voltage $\left(V_{d c}\right)$ reaches its reference quickly to 700 $\mathrm{V}$ using the proposed power factor correction controller (PFC). The PFC attests its capability to give a fast response time and to pursue the reference voltage regardless of the variation in wind speed. 
Figure 9 shows the performance of the converter with a balanced and free-harmonic voltage (Fig. 9, $a$ and $9, b)$. Figure 9,c and 9, $d$ exhibit that the injected current in

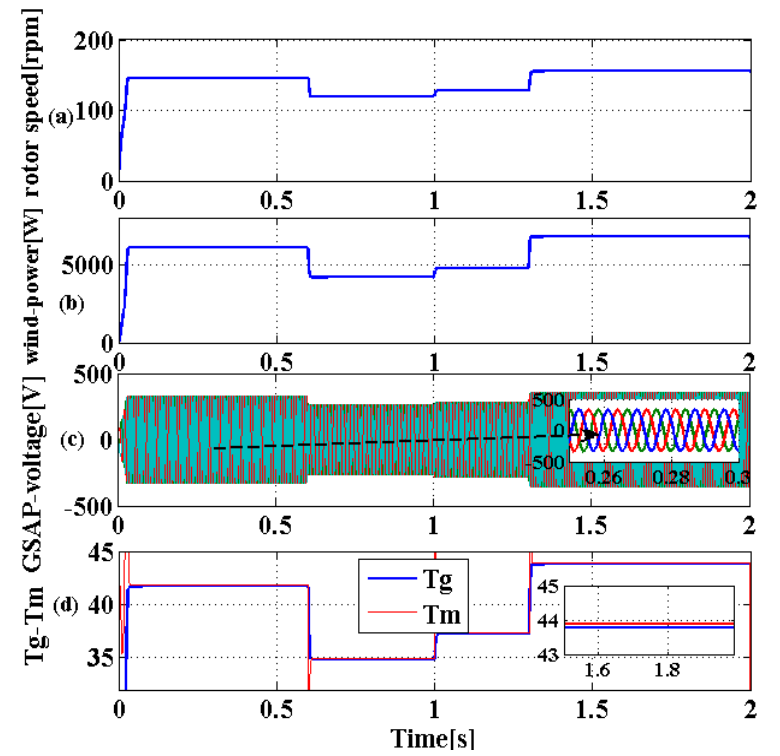

the range is controlled to be sinusoidal and balanced. Figure $9, g$ and $9, h$ indicate that the estimated active and reactive powers are identical to the measured power.

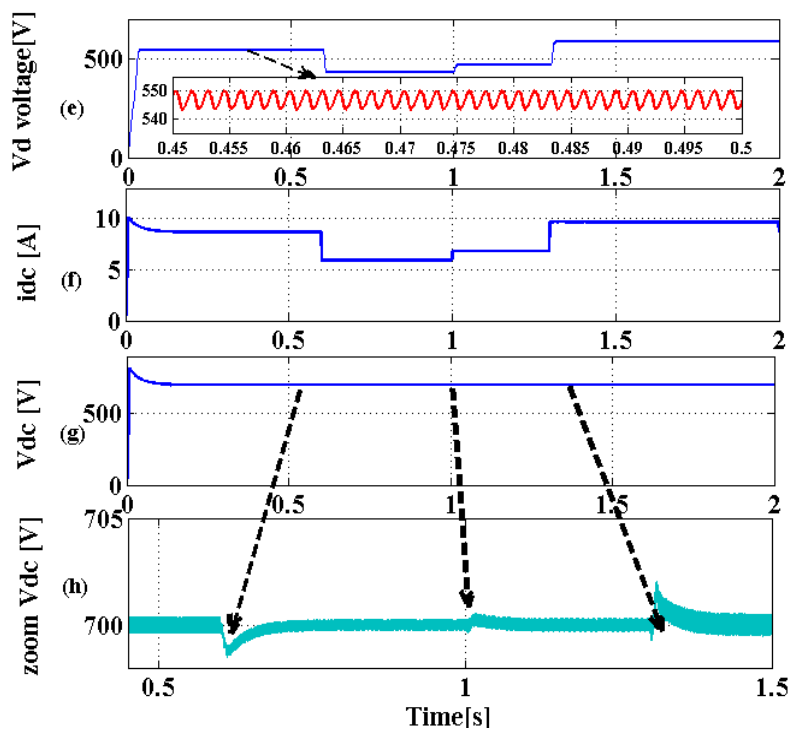

Fig. 8. System response for a change of wind speed at $9 \mathrm{~m} / \mathrm{s}$ to $7.5 \mathrm{~m} / \mathrm{s}$ to $8 \mathrm{~m} / \mathrm{s}$ to $9.5 \mathrm{~m} / \mathrm{s}$ :

$(a)$ rotor speed; $(b)$ output power; $(c)$ voltage generator; $(d)$ torque reference and generator electromagnetic torque;

$(e)$ output voltage rectifier; $(f)$ current boost converter; $(g)$ voltage boost converter; $(h)$ zoom of voltage boost converter

This indicates that the applied virtual flux DPC has high performance. The injected currents rise and drop according to the variation of the wind speed and thus the power. It can easily be shown that the dynamic response for a brusque change in the speed level is preferable for the proposed system.
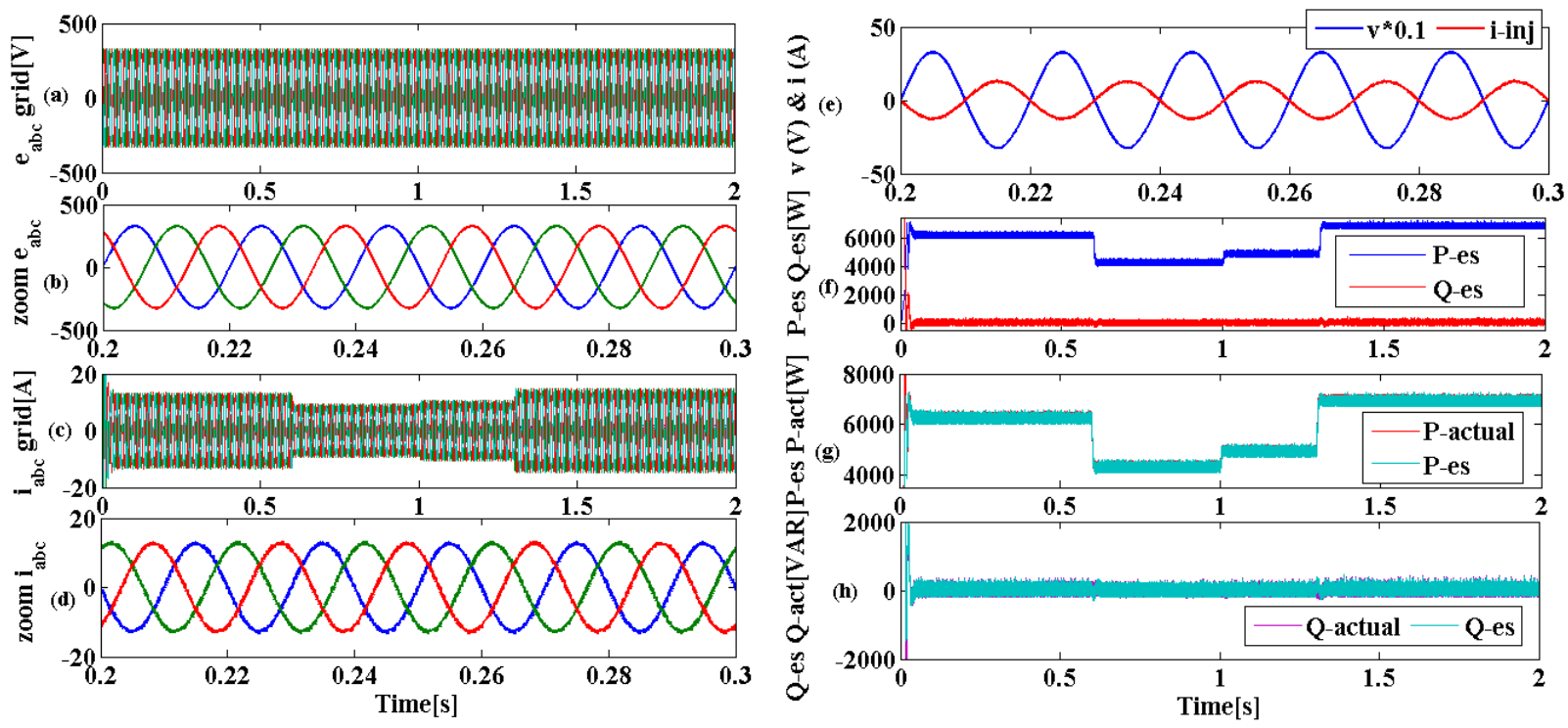

Fig. 9. Performance of the VF_DPC in a balanced and non-distorted grid during different periods of wind variation: (a) grid voltage; $(b)$ zoom grid voltage; $(c)$ grid current injected; $(d)$ zoom grid current; $(e)$ current injected with the grid voltage; $(f)$ the estimated active and reactive power; $(g)$ the active power estimated at the measured power; $(h)$ the reactive power estimated at the measured reactive power

Test 2. Simulated Transient Responses in Various Grid Voltage Conditions.

1. Without Compensation. In order to check the implementation of the VF_DPC on a two-level voltage source inverter, simulations were performed under various grid voltage conditions. Four grid voltage states are applied. Initially, the main voltages are balanced and sinusoidal, afterward, a voltage unbalance of $30 \%$ is created. secondly, the amplitude of each phase voltage is restored. But, the 5th and 7th harmonics with an amplitude of $20 \%$ are added to the fundamental. Hence, the grid voltages are balanced but distorted. Finally, the worst case of grid voltages, both unbalanced and distorted of $20 \%$ and harmonic 7 th of $20 \%$, is also included in the last condition. The curves in Fig. 10 are three-phase mains voltages, three-phase mains currents, active and reactive power. For further justification, comprehensive quantitative analyses were performed for grid voltages 
with a defined range of rate and distortion imbalance. To guarantee the normal operation of the system, the European Standard (EN 50160) recommends that the worst case for limiting THD voltage should hold at most
$8 \%$; the permissible variation of the supply voltage should not exceed $\pm 10 \%$ [14]. However, the IEEE Standard 519 recommends a THD voltage limit of $5 \%$ [15] for general applications.

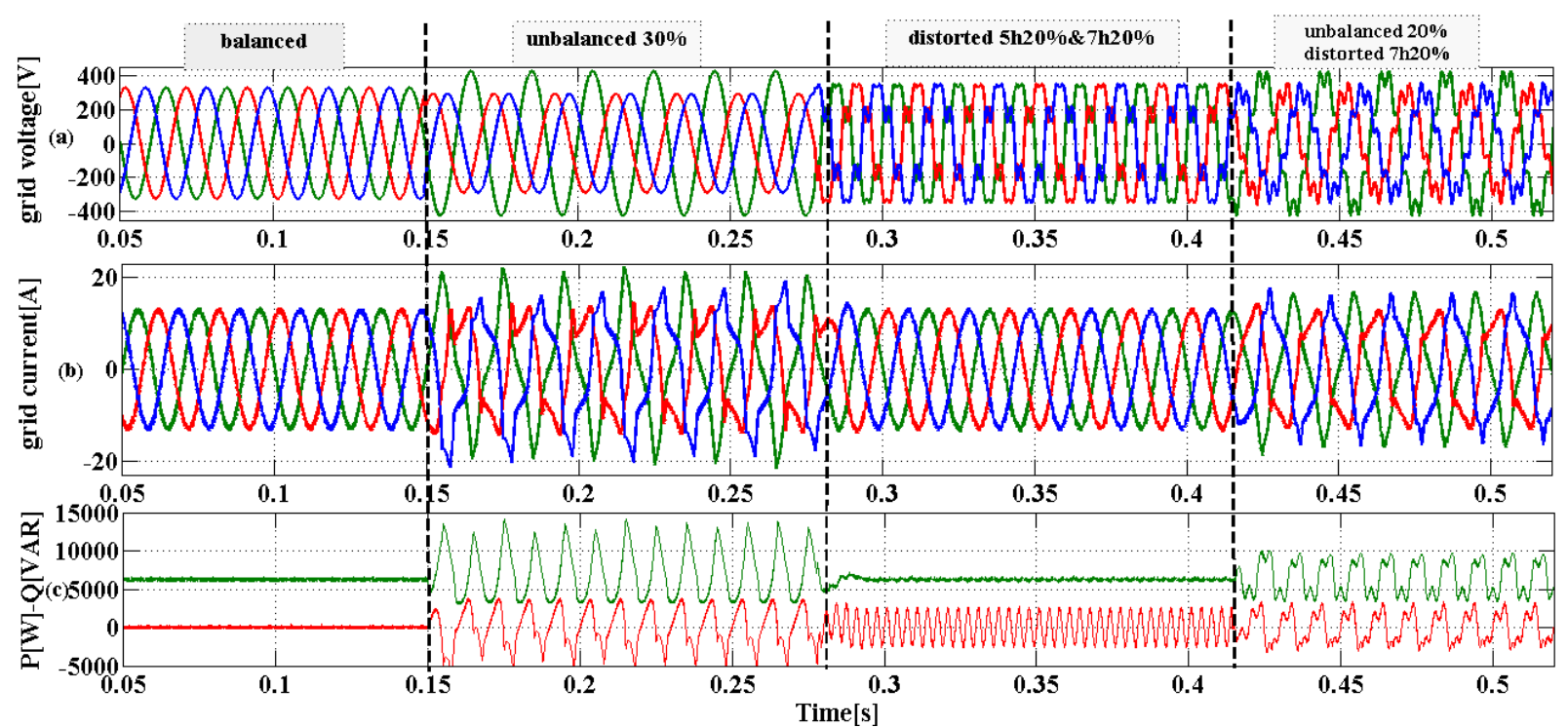

Fig. 10. The response of currents and injected power in distorted grid voltage:

(a) grid voltage; (b) grid current; $(c)$ active power and reactive power

The study is conducted to evaluate the performance of the system under different grid voltage conditions. It is seen that under balanced gate voltages, the results give a sinusoidal grid current. Table 2 shows the THD ratio of two periods for each applied condition.

\section{Currents THD}

\begin{tabular}{|c|c|c|c|c|}
\hline Case & Balanced & $\begin{array}{c}\text { Unbalanced } \\
30 \%\end{array}$ & $\begin{array}{c}\text { Distorted 5th } \\
\text { and 7th 20\% }\end{array}$ & $\begin{array}{c}\text { Unbalanced and } \\
\text { distorted 7th 20\% }\end{array}$ \\
\hline THD & $1.89 \%$ & $27.83 \%$ & $2.38 \%$ & $18.46 \%$ \\
\hline
\end{tabular}

According to Table 2, the THD of the currents is different for each condition of the applied voltages. The more unbalance in grid voltage, the more increase in THD we get, however it is not affected by the harmonic content in voltage as mentioned in [9].

2. With Proposed FV-DPC Compensation. Figures 11 and 12 show the results of the simulation after compensation. Figure 11 shows the performance of VF_DPC proposed under unbalanced and distorted voltages.

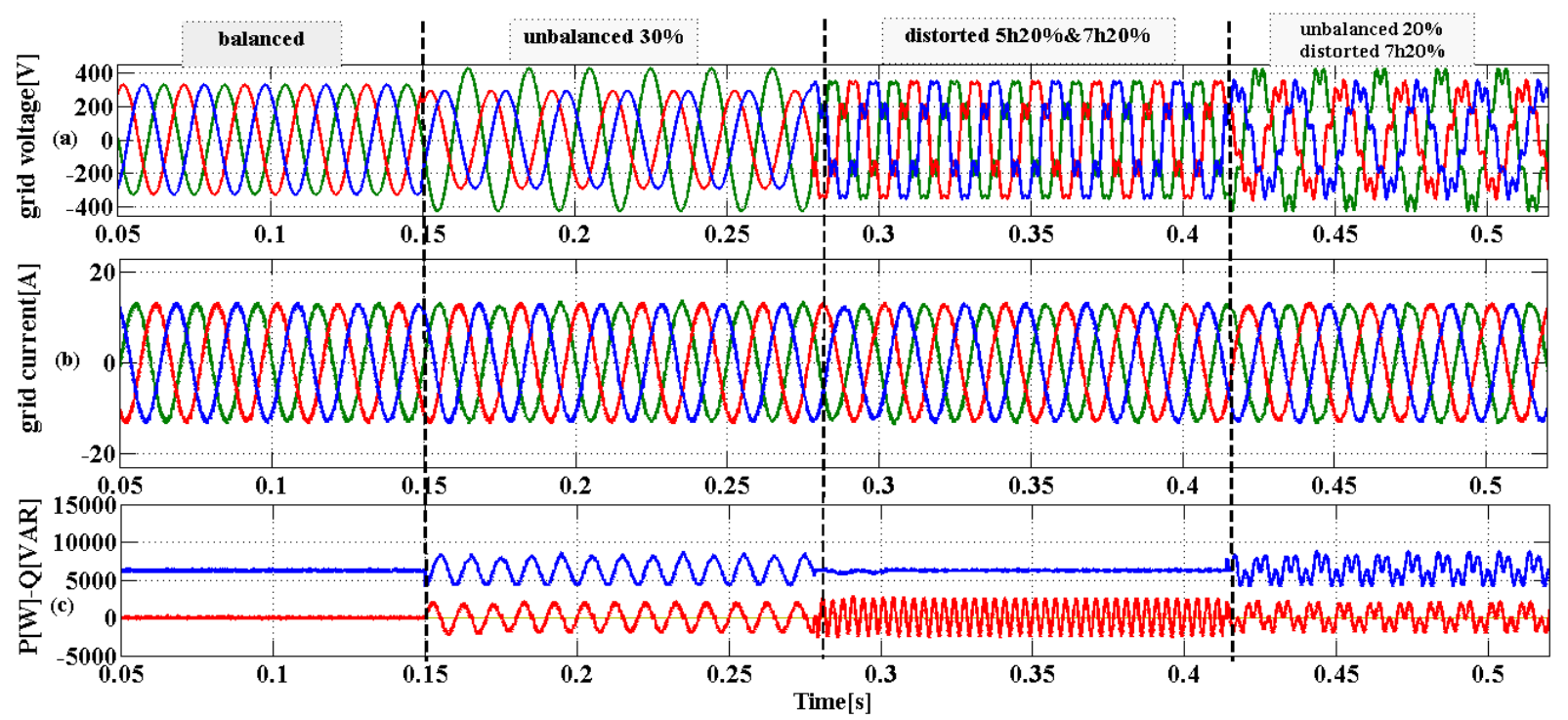

Fig. 11. The performance of the proposed VF_DPC in an unbalanced and distorted grid during different periods of wind variation: (a) grid voltage; $(b)$ grid current; (c) the active power and reactive power

As indicated in Figure 11,b, that the currents after the compensation are sinusoidal and balanced even for distorted and unbalanced voltages. The negative sequence and higher harmonic components of the gate currents are also controlled at zero. The THD of the grid currents, according to the IEEE Standard 519 harmonic, after compensation is limited. Table 3 presents the THD percentage of two periods of each condition applied. 
From Table 3, it is clear that the proposed control

Currents THD

\begin{tabular}{|c|c|c|c|c|}
\hline Case & Balanced & $\begin{array}{c}\text { Unbalanced } \\
30 \%\end{array}$ & $\begin{array}{c}\text { Distorted 5th } \\
\text { and 7th 20\% }\end{array}$ & $\begin{array}{c}\text { Unbalanced and } \\
\text { distorted 7th 20\% }\end{array}$ \\
\hline THD & $1.7 \%$ & $1.73 \%$ & $0.25 \%$ & $2.26 \%$ \\
\hline
\end{tabular}

satisfactorily compensates for distortions and imbalances under all three-phase grid conditions demonstrating the superiority and performance of the proposed control.

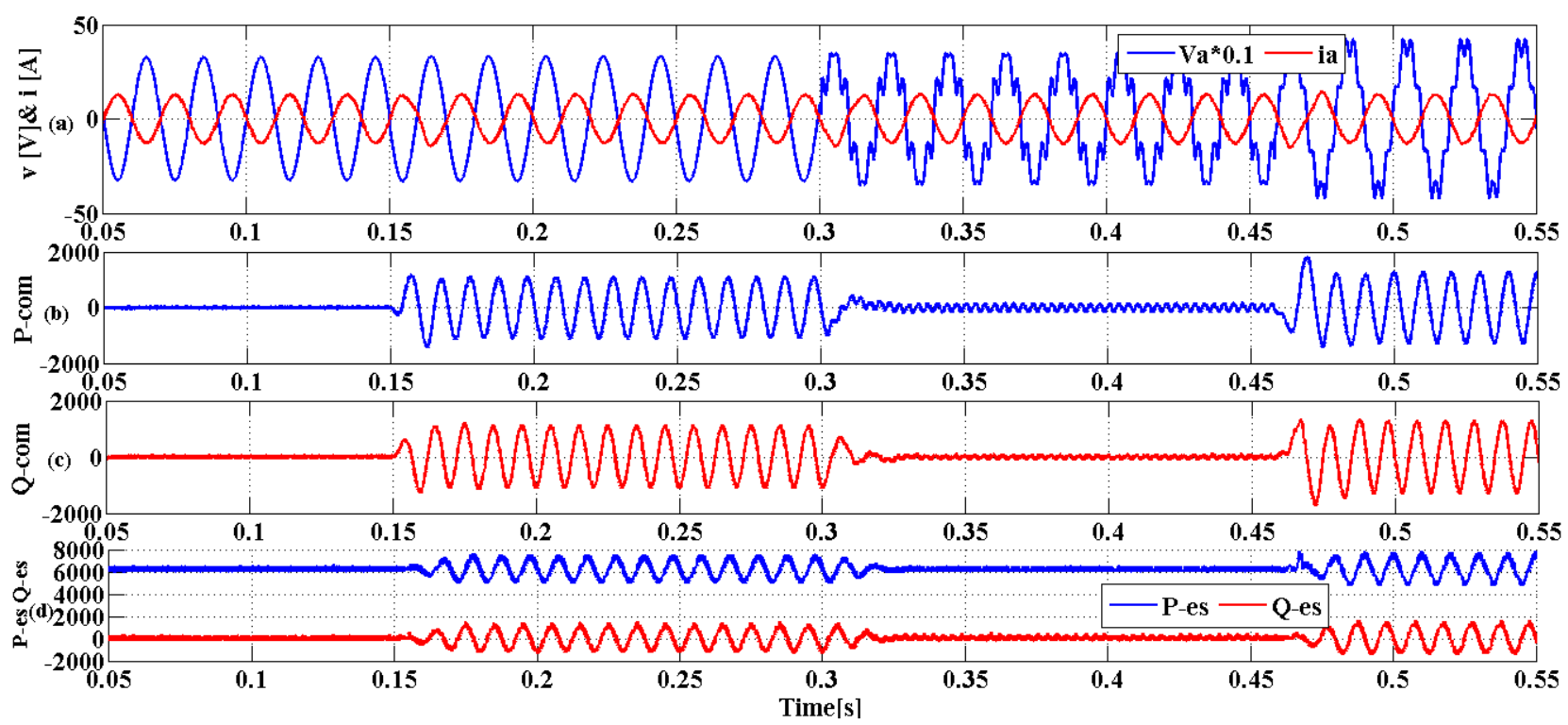

Fig. 12. Performance of the proposed VF_DPC in an unbalanced and distorted grid during different periods of wind variation: (a) grid voltage and current injected; $(b)$ active power compensation; $(c)$ reactive power compensation;

(d) reactive and active power estimated and injected into the grid

Figure $12, d$ reveals that both active and reactive powers are well controlled. The reactive power is controlled to be zero to get a unity power factor. Figure $12, b$ and 12,c show the estimation block response of compensation powers. The use of this control process removes the effect of harmonic content and unbalanced voltages on the currents. We also note that the compensating powers of the distorted part are almost null in the case of harmonics in voltages, Figure 12,b and $12, c)[0.3 \mathrm{~s} 0.55 \mathrm{~s}]$.

The following relations show how to compensate with only negative power. We have

$$
\begin{aligned}
& P_{\text {har }}=\omega \times\left[\left(\varphi_{s \alpha}^{h} \times i_{s \beta}^{+}-\varphi_{s \beta}^{h} \times i_{s \alpha}^{+}\right)\right] \cong 0 ; \\
& Q_{\text {har }}=\omega \times\left[\left(\varphi_{s \alpha}^{h} \times i_{s \alpha}^{+}+\varphi_{s \beta}^{h} \times i_{s \beta}^{+}\right)\right] \cong 0 .
\end{aligned}
$$

So, it becomes

$$
\begin{aligned}
& P_{\text {com }}=\omega \times\left[\left(\varphi_{s \alpha}^{-} \times i_{s \beta}^{+}-\varphi_{s \beta}^{-} \times i_{s \alpha}^{+}\right)\right] ; \\
& Q_{c o m}=\omega \times\left[\left(\varphi_{s \alpha}^{-} \times i_{s \alpha}^{+}+\varphi_{s \beta}^{-} \times i_{s \beta}^{+}\right)\right] .
\end{aligned}
$$

Figure 13 shows the simulation results with only negative power compensation.

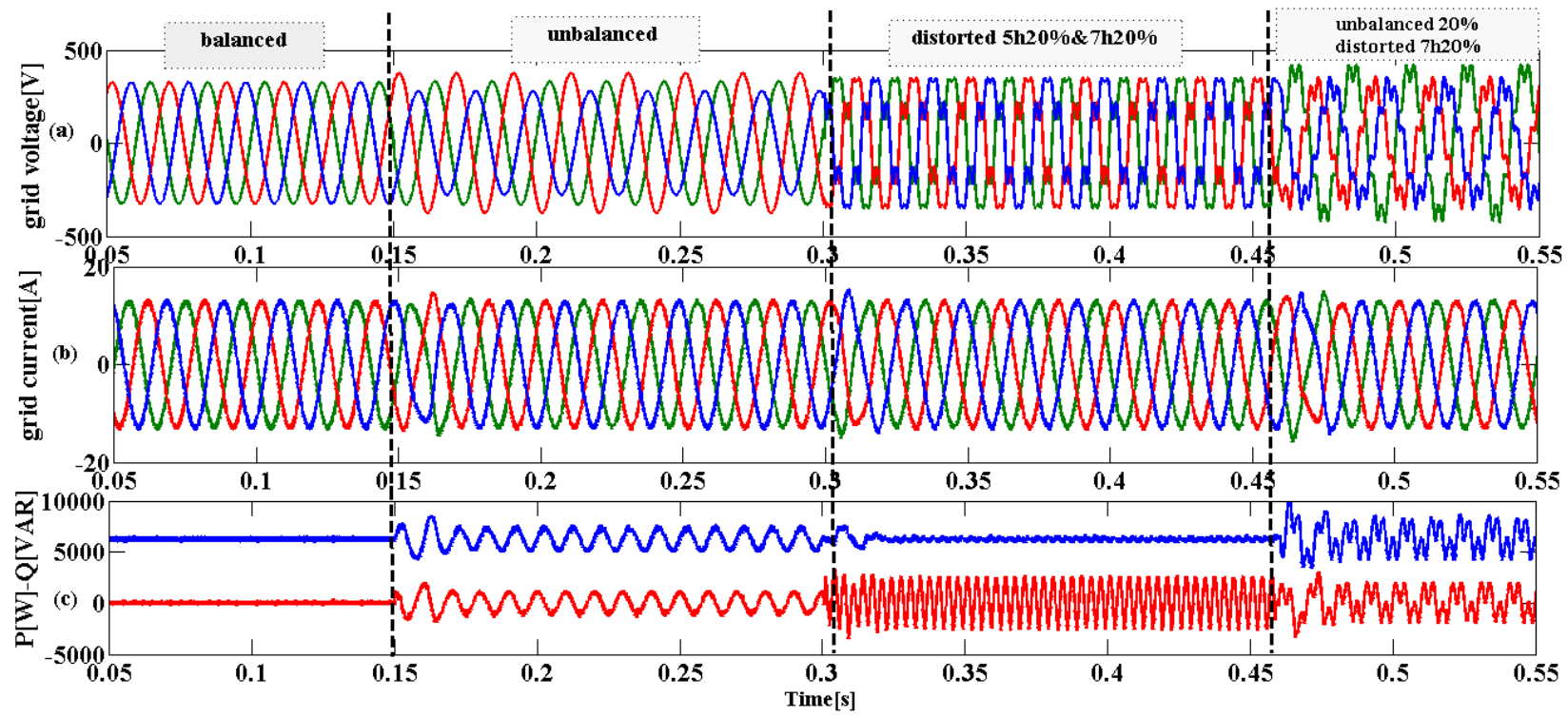

Fig. 13. The performance of VF_DPC with only negative power compensation: (a) grid voltage; (b) grid current; (c) active and reactive powers 
Figure 13 shows that this method (compensation with negative powers) gives almost the same results similar to the previous method in terms of THD as shown in Table 4, except that a delay in response is estimated for one period. This is shown in Figure 13,b.

Table 4 presents the THD percentage of two periods of each condition applied.

Currents THD

\begin{tabular}{|c|c|c|c|c|}
\hline Case & Balanced & $\begin{array}{c}\text { Unbalanced } \\
30 \%\end{array}$ & $\begin{array}{c}\text { Distorted 5th } \\
\text { and 7th 20\% }\end{array}$ & $\begin{array}{c}\text { Unbalanced and } \\
\text { distorted 7th 20\% }\end{array}$ \\
\hline THD & $1.7 \%$ & $1.9 \%$ & $2.22 \%$ & $2.53 \%$ \\
\hline
\end{tabular}

Conclusion.

This article proposes a strategy of controlling a micro wind turbine based on a PMSG by injecting maximum power and adapting to all disturbances that occur in the grid.

For this, a new control strategy VF_DPC is suggested for the grid converter. Thanks to the efficiency of the proposed controller, the three-phase grid currents are effectively regulated to be balanced and sinusoidal with very low direct current component despite deformed and unbalanced grid voltages. All the results are obtained at the maximum power of the wind turbine $P_{\text {ref }}{ }^{*}[\mathrm{~W}]$ and $Q_{\text {ref }}{ }^{*}$ of 0 [VAR].

The total harmonic distortion and the direct current component of the grid current are still kept very low and completely comply with European Standard (EN 50160) and IEEE Standard 519.

The simulation results gave $2.26 \%$ for umbalanced and distorted voltage. In addition to good steady-state performance, this controller also provides a very fast dynamic response under the reference variation. The use of this control process removes the effect of harmonic content and unbalanced voltages on the currents.

The proposed current control scheme can be implemented without the need for grid-side voltage sensors; it can be easily integrated into the grid with reduced cost.

\section{APPENDIX}

Parameters of wind turbine

\begin{tabular}{|c|c|c|}
\hline Parameter & Symbol & Value \\
\hline Power & $P_{t}$ & $7.5 \mathrm{~kW}$ \\
\hline Radius & $R$ & $3.24 \mathrm{~m}$ \\
\hline Rated wind speed & $N$ & $296 \mathrm{rpm}$ \\
\hline Wind speed range & $V_{\text {cut-in }}, V_{\max }$ & $4-12 \mathrm{~m} / \mathrm{s}$ \\
\hline Inertia & $J_{t}$ & $7.5 \mathrm{~kg} \cdot \mathrm{m}^{2}$ \\
\hline Friction coefficient & $B_{t}$ & $0.06 \mathrm{~N} \cdot \mathrm{m} \cdot \mathrm{s} / \mathrm{rad}$ \\
\hline
\end{tabular}

Micro grid parameters: $V_{\mathrm{rms}}=230 \mathrm{~V}, R_{s}=0.1 \Omega$, $L_{s}=0.01 \mathrm{H}, N=50$.

Parameters of PMSG

\begin{tabular}{|c|c|c|}
\hline Parameter & Symbol & Value \\
\hline Rated power & $P_{g}$ & $6 \mathrm{~kW}$ \\
\hline Rated torque & $T_{g}$ & $40 \mathrm{~N} \cdot \mathrm{m}$ \\
\hline Rated current & $I$ & $12 \mathrm{~A}$ \\
\hline Rated speed & $v$ & $153 \mathrm{rad} / \mathrm{sec}$ \\
\hline Number of poles & $p$ & 10 \\
\hline Magnet flux linkage & $\varphi m$ & $0.433 \mathrm{~Wb}$ \\
\hline Armature resistance & $R_{a}$ & $0.425 \Omega$ \\
\hline Stator inductance & $L_{s}$ & $8.4 \mathrm{mH}$ \\
\hline
\end{tabular}

\section{REFERENCES}

1. Mendis N., Muttaqi K.M., Sayeef S., Perera S. Standalone Operation of Wind Turbine-Based Variable Speed Generators With Maximum Power Extraction Capability," IEEE Transactions on Energy Conversion, vol. 27, no. 4, pp. 822-834, Dec. 2012. doi: 10.1109/tec.2012.2206594.

2. Barote L., Marinescu C., Cirstea M.N. Control Structure for Single-Phase Stand-Alone Wind-Based Energy Sources. IEEE Transactions on Industrial Electronics, 2013, vol. 60, no. 2, pp. 764-772. doi: 10.1109/tie.2012.2206346.

3. Zammit D., Staines C.S., Micallef A., Apap M., Licari J. Incremental Current Based MPPT for a PMSG Micro Wind Turbine in a Grid-Connected DC Microgrid. Energy Procedia, 2017, vol. 142, pp. 2284-2294. doi: 10.1016/j.egypro.2017.12.631.

4. Venkatraman R., Bhat A. K. S. Large-signal transient analysis of a soft-switching, two-switch AC-to-DC converter. IEE Proceedings - Circuits, Devices and Systems, 2000, vol. 147, no. 2, pp. 146-152. doi: 10.1049/ip-cds:20000177.

5. Razali A.M., Rahman M.A. Virtual grid flux oriented control method for front-end three phase boost type voltage source rectifier. 2012 25th IEEE Canadian Conference on Electrical and Computer Engineering (CCECE), Montreal, Quebec, Canada, Apr. 2012. doi: 10.1109/ccece.2012.6334922.

6. Dannehl J., Wessels C., Fuchs F.W. Limitations of VoltageOriented PI Current Control of Grid-Connected PWM Rectifiers With LCL Filters. IEEE Transactions on Industrial Electronics, 2009, vol. 56, no. 2, pp. 380-388. doi: 10.1109/tie.2008.2008774.

7. Xu Lie, Zhi Dawei, Williams B.W. Predictive Current Control of Doubly Fed Induction Generators. IEEE Transactions on Industrial Electronics, 2009, vol. 56, no. 10, pp. 4143-4153. doi: 10.1109/tie.2009.2017552.

8. Lorenz R.D., Lipo T.A., Novotny D.W. Motion control with induction motors. Proceedings of the IEEE, 1994, vol. 82, no. 8, pp. 1215-1240. doi: 10.1109/5.301685.

9. Lee S.S., Heng Y.E. Table-based DPC for grid connected VSC under unbalanced and distorted grid voltages: Review and optimal method. Renewable and Sustainable Energy Reviews, 2017, vol. 76, pp. 51-61. doi: 10.1016/j.rser.2017.03.033.

10. Malinowski M. Sensorless Control Strategies for ThreePhase PWM Rectifiers. Ph.D. Thesis Warsaw University of Technology Faculty of Electrical Engineering Institute of Control and Industrial Electronics. Warsaw, Poland, 2001.

11. Zheng Z., Wang C. Research on Direct Power Control Strategy for PWM Rectifier. 2010 International Conference on Future Power and Energy Engineering, Jun. 2010. doi: 10.1109/ICFPEE.2010.30.

12. Lauria D., Coppola M. Design and control of an advanced PV inverter. Solar Energy, 2014, vol. 110, pp. 533-542. doi: 10.1016/j.solener.2014.09.040.

13. Hussein M.M., Senjyu T., Orabi M., Wahab M.A.A., Hamada M.M. Load power management control for a stand alone wind energy system based on the state of charge of the battery. 2012 IEEE International Conference on Power and Energy (PECon), Dec. 2012. doi: 10.1109/pecon.2012.6450352. 14. European Standard EN 50160. Voltage characteristics of electricity supplied by public distribution systems. CENELEC, 2005.

15. IEEE Std 519-1992. IEEE Recommended Practices and Requirements for Harmonic Control in Electrical Power Systems, 1993, 112 p. doi: 10.1109/IEEESTD.1993.114370.

16. Allagui M., Hasnaoui O.B.k., Belhadj J. A $2 \mathrm{MW}$ direct drive wind turbine; vector control and direct torque control techniques comparison. Journal of Energy in Southern Africa, 2017, vol. 25 , no. 2, pp. 117-126. doi: 10.17159/24133051/2014/v25i2a2679.

17. Prasad A.R., Ziogas P.D., Manias S. An active power factor correction technique for three-phase diode rectifiers. 
IEEE Transactions on Power Electronics, 1991, vol. 6, no. 1, pp. 83-92. doi: 10.1109/63.65006.

18. Mohd Yusoff N.A., Razali A.M., Abdul Karim K., Sutikno T., Jidin A. A Concept of Virtual-Flux Direct Power Control of Three-Phase AC-DC Converter. International Journal of Power Electronics and Drive Systems (IJPEDS), 2017, vol. 8, no. 4, pp. 1776-1784. doi: 10.11591/ijpeds.v8.i4.pp1776-1784.

19. Verdelho P., Marques G.D. DC voltage control and stability analysis of PWM-voltage-type reversible rectifiers IEEE Transactions on Industrial Electronics, 1998, vol. 45, no. 2, pp. 263-273. doi: 10.1109/41.681225.

20. Xiang L., Minxiao H. Direct Virtual Power Control Telkomnika, 2014, vol. 12, no. 7, pp. 5144-5153 doi: 10.11591/telkomnika.v12i7.5806.

21. Malinowski M., Kazmierkowski M. Simple Direct Power Control of Three-Phase PWM Rectifier Using Space Vector Modulation - A Comparative Study. EPE Journal, 2003, vol. 13, no. 2, pp. 28-34. doi: 10.1080/09398368.2003.11463529.

22. Malinowski M., Kazmierkowski M.P., Hansen S., Blaabjerg F., Marques G.D. Virtual-flux-based direct power control of three-phase PWM rectifiers. IEEE Transactions on Industry Applications, 2001, vol. 37, no. 4, pp. 1019-1027. doi: $\mathbf{1 0 . 1 1 0 9 / 2 8 . 9 3 6 3 9 2 . ~}$

23. Rahab A., Senani F., Benalla H. Direct Power Control of Three-Phase PWM Rectifier based DSOGI-VF Estimator for No-Ideal LineVoltages Conditions. Int. Journal of Engineering Research and Application, 2018, vol. 8, iss. 1 (part-1), pp. 1018. doi: 10.9790/9622-0801011018.

24. Bouafia A., Gaubert J.P., Chaoui A. Direct Power Control Scheme Based on Disturbance Rejection Principle for ThreePhase PWM AC/DC Converter under Different Input Voltage Conditions. Journal of Electrical Systems, 2012, vol. 8, iss. 4, pp. 367-383.

How to cite this article:

Boukhechem I., Boukadoum A., Boukelkoul L., Lebied R. Sensorless direct power control for three-phase grid side converter integrated into wind turbine system under disturbed grid voltages. Electrical engineering \& electromechanics, 2020, no. 3, pp. 48-57. doi: 10.20998/2074-272X.2020.3.08.
25. Suul J.A., Undeland T. Impact of Virtual Flux reference frame orientation on voltage source inverters in weak grids. The 2010 International Power Electronics Conference - ECCE $A S I A$, Jun. 2010. doi: 10.1109/ipec.2010.5542230.

26. Malinowski M., Kazmierkowski M.P., Hansen S., Blaabjerg F., Marques G.D. Virtual-flux-based direct power control of three-phase PWM rectifiers. IEEE Transactions on Industry Applications, 2001, vol. 37, no. 4, pp. 1019-1027. doi:

27. Haque M.E., Negnevitsky M., Muttaqi K.M. A Novel Control Strategy for a Variable Speed Wind Turbine with a Permanent Magnet Synchronous Generator. 2008 IEEE Industry Applications Society Annual Meeting, Oct. 2008. doi: 10.1109/08ias.2008.374.

Received 10.02.2020

Ismail Boukhechem ${ }^{1}$, Ph.D.,

Ahcen Boukadoum ${ }^{1}$, Doctor of Electrotechnical, Professor,

Lahcene Boukelkoul ${ }^{1}$, Doctor of Electrotechnical,

Rima Lebied ${ }^{1}$, Ph.D.,

${ }^{1}$ Electrotechnical Laboratory Skikda (LES),

University 20 August 1955,

26 Road El Hadaiek 21000, Skikda, Algeria.

e-mail: sameu25@gmail.com, boukadoum2003@yahoo.fr,

1_boukel@yahoo.co.uk, rima42453@gmail.com 10.1109/28.936392. 